\title{
Dependence of induction of enterobacterial AmpC $\beta$-lactamase on cell-wall peptidoglycan, as demonstrated in Proteus mirabilis and its wall-less protoplast L-form
}

\author{
Michael Tölg, Herbert Schmidt, Ralph Schierl, Martina Datz and Hans H. Martin* \\ Institut für Mikrobiologie, Technische Hochschule Darmstadt, Schnittspahnstrasse 9, D-64287 Darmstadt, FRG
}

(Received 5 February 1993; revised 17 May 1993; accepted 18 June 1993)

\begin{abstract}
The mobilizable plasmid pMD101 (ampR, ampC) was constructed by inserting cloned ampC, the structural gene for the chromosomal AmpC $\beta$-lactamase of Citrobacter freundii, and the closely linked ampR encoding the transcriptional regulator essential for enzyme induction, into the broad host-range plasmid pKT231. Plasmid pMD101 was transconjugated into Proteus mirabilis VI and its isogenic, cell-wall-less protoplast L-form LVI. AmpC $\beta$-lactamase was expressed constitutively from cloned $\operatorname{ampR}$ and $a m p C$ in bacteria and in some L-form protoplasts. However, induction of the enzyme by $\beta$-lactam antibiotics occurred only in bacterial cells and not in the cell-wall- and peptidoglycan-deficient L-form. In agreement with current models, induction of AmpC $\beta$ lactamase is thought to be initiated by an induction signal arising from the metabolic disturbance of cell-wall peptidoglycan.
\end{abstract}

\section{Introduction}

Chromosomally encoded class $1 \beta$-lactamase (Sykes \& Smith, 1979; molecular class C, Jaurin \& Grundström, 1981) occurs in different Gram-negative bacteria. The enzyme is normally synthesized constitutively at low levels but can be induced to much higher concentrations by $\beta$-lactam antibiotics with a corresponding increase of bacterial resistance to these antibiotics. In Citrobacter freundii and Enterobacter cloacae, induced expression of the $\beta$-lactamase from the chromosomal gene ampC has been shown to be under the control of several regulatory genes. These include $a m p R$, closely linked to $a m p C$, encoding a transcriptional regulator (Lindberg et al., 1985; Honoré et al., 1986; Lindquist et al., 1989a), and the ampD-ampE operon, responsible for negative modulation of $\beta$-lactamase synthesis (Lindberg et al., 1987; Honoré et al., 1989; Lindquist et al., 1989b). The more recently discovered gene ampG (Korfmann \& Sanders, 1989 ) is thought to encode a membrane-bound transducer of an external induction signal (Lindquist et al., 1993). As suggested by these authors, the transducer may modify the external signal and relay the product as activator to the transcriptional regulator AmpR. In the

*Author for correspondence. Tel. +49615163391 ; fax +496151 164808 . absence of induction, function of ampD,E diverts much of the moderate signal inflow from AmpG, either by direct signal inactivation or by inhibition of $A m p R$ function, thus allowing only low-level constitutive $\beta$ lactamase synthesis. Induction by $\beta$-lactam antibiotics presumably increases signal production above the inactivating capacity of $a m p D, E$ and causes large-scale activation of AmpR and expression of AmpC $\beta$ lactamase. The negative control function of $a m p D$ has been demonstrated in mutants where defects in ampD result either in high (semi-)constitutive or in hyperinducible $\beta$-lactamase synthesis (Lindberg et al., 1987; Lindquist et al., 1989b; Honoré et al., 1989). Genes ampD,E (Lindberg et al., 1987; Honoré et al., 1989; Lindquist et al., 1989b) and ampG (G. Korgmann, personal communication; Lindquist et al., 1993) are also present in Escherichia coli. Here, AmpC $\beta$-lactamase is normally non-inducible because of deletion of ampR, but becomes inducible upon introduction of cloned $a m p C$ and $a m p R$ from $C$. freundii.

The nature of the signal interacting with ampG or its product and the way in which it originates from the action of the inducing $\beta$-lactam are so far unknown. The bacterial cytoplasmic membrane is thought to be impermeable to $\beta$-lactam antibiotics, and it has been shown that penetration of the antibiotics into the cytoplasm is not required for induction (Everett et al., 1990). In a 
model proposed by Lindberg et al. (1985, 1988), the initiation of $\beta$-lactamase induction is viewed as an additional effect of the interaction of $\beta$-lactams with one or several of the penicillin-binding proteins on the outer surface of the cytoplasmic membrane. The ensuing inactivation of the function of penicillin-binding proteins and disorganization of bacterial peptidoglycan synthesis may then cause the formation of one or more peptidoglycan catabolites with the function of indirect induction signals ('autoinducer'). Evidence for a link between the regulation of AmpC $\beta$-lactamase and the biosynthesis of peptidoglycan has also been provided by Tuomanen $e t$ al. (1991). Induction of $\beta$-lactamase would thus depend on the presence of a cell wall and peptidoglycan. In agreement with this hypothesis, we show here that AmpC $\beta$-lactamase is expressed constitutively and inducibly from cloned $a m p R$ and $a m p C$ of $C$. freundii in normal bacteria of Proteus mirabilis, but only constitutively in the isogenic protoplast $\mathrm{L}$-form derived from this bacterium. The L-form organisms have been shown previously to be viable, wall-less protoplasts devoid of a peptidoglycan layer and outer membrane (Martin, 1964; Hofschneider \& Martin, 1968; Kroll et al., 1980).

\section{Methods}

Bacteria and plasmids. P. mirabilis VI and the protoplast L-form LVI were described by Taubeneck (1962a,b), Martin (1964) and Hofschneider \& Martin (1968). E. coli HfrH (Low, 1973) and SN0301 $(a m p C 8, \beta$-lactamase-deficient; $a m p D 1$, Lindquist et al., 1989b) were reference strains for inducible and hyperinducible expression of $\beta$ lactamase, respectively, from cloned ampR and ampC. E. coli $\mathrm{S} 17-1$ (pro thi; Simon, 1989) was used as auxotrophic donor for the transconjugation of mobilizable plasmids. E. coli FL01 (Lindberg \& Normark, 1987) served as restriction-deficient host for plasmid construction.

The adjacent genes $a m p R$ and $a m p C$ on a $7.5 \mathrm{~kb} E c o \mathrm{RI}$ fragment from $C$. freundii were obtained from the original cloning product, plasmid pNU302 (Lindberg et al., 1985). Subcloned $a m p R$ and $a m p C$ on pNU305 (vector pBR322, Tc ${ }^{\mathrm{R}}$; Lindberg et al., 1985) and pNU344 (vector pACYC184, $\mathrm{Cm}^{\mathrm{R}}$; Lindberg et al., 1987) were used for transformation experiments into $P$. mirabilis and as references for $\beta$ lactamase expression in $E$. coli. The mobilizable plasmid pKT231 $\left(\mathrm{Km}^{\mathrm{R}} \mathrm{Sm}^{\mathrm{R}}\right.$, Bagdasarian et al., 1981) was the vector for the construction of plasmid pMD101 (ampR ampC $\mathrm{Km}^{\mathrm{R}}$ ). Its size was determined as $13.3 \mathrm{~kb}$ by restriction analysis. Plasmid pGKS273-3 (vector pACYC184, ampG, $\mathrm{Cm}^{\mathrm{R}}$ ) with cloned ampG from $E$. coli was kindly made available by Dr Gisela Korfmann (Bayer A. G., Leverkùsen, Germany).

Growth media. LB broth and agar medium for $E$. coli was supplemented with $2 \mathrm{~g}$ glucose $\mathrm{l}^{-1}$ and $1 \mathrm{mg}$ thiamin $\mathrm{l}^{-1}$ (Lindberg $e t$ al., 1987). Minimal media were M9CA medium (Lindberg et al., 1987) supplemented with $2 \mathrm{~g}$ Casamino acids (Difco) $\mathrm{1}^{-1}, 50 \mathrm{mg}$ uracil $\mathrm{l}^{-1}$, $50 \mathrm{mg}$ L-tryptophan $\mathrm{l}^{-1}$ and $1 \mathrm{mg}$ thiamin $\mathrm{l}^{-1}$ for $E$. coli, and the medium of Grabow \& Smit (1967) for P. mirabilis. Growth of individual, non-swarming colonies of $P$. mirabilis was obtained on the $\mathrm{NaCl}$-deficient, high-glucose agar medium of Naylor (1964). This was modified to contain $10 \mathrm{~g}$ tryptone (Oxoid) $\mathrm{l}^{-1}, 5 \mathrm{~g}$ yeast extract (Oxoid) $\mathrm{1}^{-1}, 10 \mathrm{~g}$ glucose $\mathrm{1}^{-1}$ and $20 \mathrm{~g}$ agar $\mathrm{l}^{-1}$.

Bacteria and L-form protoplasts of $P$. mirabilis were grown in the modified L-form medium of Martin et al. (1975) containing $\left(1^{-1}\right): 15 \mathrm{~g}$ beef extract Lab Lemco (Oxoid), $2 \mathrm{~g}$ glucose, $5 \mathrm{~g} \mathrm{NaCl}$ and $4.5 \mathrm{~g}$ $\mathrm{Na}_{2} \mathrm{HPO}_{4}, 2 \mathrm{H}_{2} \mathrm{O}$. Agar medium for the L-form was supplemented with $100 \mathrm{ml}$ horse serum (Oxoid) $1^{-1}$. L-form protoplasts for polyethylene glycol transformation were grown in modified LFS medium (Klessen $e t$ al., 1989), containing $\left(1^{-1}\right): 3 \mathrm{~g}$ beef extract Lab Lemco (Oxoid), $10 \mathrm{~g}$ Bacto Peptone (Difco), $5 \mathrm{~g}$ yeast extract (Oxoid), $5 \mathrm{~g} \mathrm{NaCl}$ and $20 \mathrm{~g}$ sucrose.

The following $\beta$-lactam compounds were used: cephalothin and cephalexin (Eli Lilly), cefotaxime (Hoechst), aztreonam (Squibb), cefoxitin and imipenem (Merck, Sharp \& Dohme), 6-amino penicillanic acid (Bayer) and nitrocefin (Glaxo).

DNA techniques. For the isolation of plasmid DNA, digestion with restriction endonucleases, separation of DNA fragments by agarose gel electrophoresis, and ligation of DNA fragments, standard procedures (Sambrook et al., 1989) were used. Purification of plasmid DNA on a preparative scale was carried out with the Qiagen Plasmid Midi Kit (Qiagen) according to the manufacturer's instructions.

Construction of plasmid pMD101 ( $\mathrm{ampR}$ ampC Km $\mathrm{m}^{R}$ ) from $\mathrm{pKT} 231$ $\left(\mathrm{Km}^{R} \mathrm{Sm}^{R}\right)$. Cloning of $a m p R$ and $a m p C$ into the streptomycin marker of pKT231 and preservation of kanamycin resistance was necessary to allow the introduction of pMD101 and assay of ampR and $a m p C$ function in the streptomycin-resistant $E$. coli reference strains. From pNU302 (Lindberg et al., 1985), the $C$. freundii-derived $7.5 \mathrm{~kb}$ fragment containing cloned $a m p R$ and $a m p C$ was excised by $E c o$ RI endonuclease and purified. Vector pKT231 $(13 \cdot 3 \mathrm{~kb})$ was cut by $E c o$ RI at the unique EcoRI site in the promoter region essential for transcription of the streptomycin resistance gene (Bagdasarian et al., 1981). The $7.5 \mathrm{~kb}$ $a m p R$ and $a m p C$-containing fragment was ligated into the linearized vector. The ligation product was transformed into $E$. coli FL01, and colonies of transformants were grown on LB-agar medium containing $100 \mu \mathrm{g}$ kanamycin $\mathrm{ml}^{-1}$. Colonies containing the desired hybrid plasmid pMD101 (ampR ampC $\mathrm{Km}^{\mathrm{R}} \mathrm{Sm}^{\mathrm{S}}$ ) were identified by their inability to grow on replica plates of the original transformant colonies on LBagar medium containing $100 \mu \mathrm{g}$ streptomycin $\mathrm{ml}^{-1}$. Plasmid pMD101 was isolated from hybrid-plasmid-containing bacteria and its size was determined as $20.8 \mathrm{~kb}$ by restriction analysis.

Plasmid transfer procedures. All plasmids were transformed into $E$. coli strains by the $\mathrm{CaCl}_{2}$ technique (Mandel \& Higa, 1970) or by the procedure of Hanahan (1983). Plasmids pKT231 $\left(\mathrm{Km}^{\mathrm{R}} \mathrm{Sm}^{\mathrm{R}}\right)$ and pMD101 ( $a m p R a m p C \mathrm{Km}^{\mathrm{R}}$ ) were transconjugated into cells and $\mathrm{L}$ form protoplasts of $P$. mirabilis from the auxotrophic donor $E$. coli S17-1(pKT231) and S17-1(pMD101). For liquid mating, $P$. mirabilis $\mathrm{VI}$ and the donor $E$. coli strains were grown at $37^{\circ} \mathrm{C}$ in shake cultures of $30 \mathrm{ml} \mathrm{L}$-form medium to an $\mathrm{OD}_{578}$ of 0.8 . After 10 -fold dilution of the donor $E$. coli cultures with sterile $\mathrm{L}$-form medium, $2 \mathrm{ml}$ of $P$. mirabilis VI culture and of dilute donor cultures were mixed and incubated at $37^{\circ} \mathrm{C}$ for $2 \mathrm{~h}$ with slow shaking. Then, cells from $1.5 \mathrm{ml}$ mating mixture were sedimented by centrifugation and freed from the L-form medium by two consecutive washings in $0.05 \mathrm{M}$-phosphate

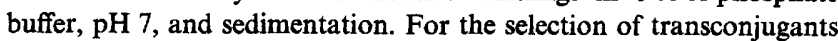
of $P$. mirabilis VI and elimination of auxotrophic $E$. coli, different dilutions of the resuspended sediment in phosphate buffer were plated on Grabow-Smit minimal agar medium containing $200 \mu \mathrm{g}$ kanamycin $\mathrm{ml}^{-1}$ and incubated for $2 \mathrm{~d}$ at $37^{\circ} \mathrm{C}$. Cells from the colonies obtained were restreaked twice on the same selective agar medium to isolate individual clones of transconjugants. The presence of the respective plasmids in the transconjugants was verified by standard plasmid analysis. No growth appeared on control platings of $E$. coli donor bacteria and of $P$. mirabilis VI on the kanamycin-minimal agar medium. 
Transconjugation of pMD101 into LVI protoplasts was carried out by filter mating of donor $E$. coli S17-1(pMD101) and L-form protoplasts grown as described for liquid mating. A mixture of $0.25 \mathrm{ml}$ donor and $1 \mathrm{ml}$ protoplast cultures was partially sedimented. After removal of the clear supernatant the concentrated mating suspension was spread on a prewashed, sterilized and dried Millipore filter $(50 \mathrm{~mm}$ diam., $0.22 \mu \mathrm{m}$ pore size). The filter was placed on the surface of an $\mathrm{L}$ form agar plate and incubated for $4 \mathrm{~h}$ at $37^{\circ} \mathrm{C}$. L-form transconjugants were selected by transferring the mating filter into liquid $\mathrm{L}$-form medium containing $100 \mu \mathrm{g}$ kanamycin $\mathrm{ml}^{-1}$ and $200 \mu \mathrm{g}$ cycloserine $\mathrm{ml}^{-1}$ for the elimination of the $E$. coli donor by inhibition of peptidoglycan synthesis. After incubation for $24 \mathrm{~h}$ at $30^{\circ} \mathrm{C}$, turbidity of the medium and microscopic observation of a protoplast population indicated L-form growth. Subsequent subculture in L-form medium with kanamycin and cycloserine, and then with $100 \mu \mathrm{g}$ kanamycin ml $\mathrm{m}^{-1}$ alone yielded cultures of uniform L-form protoplasts. Individual clones of LVI(pMD101) were then obtained by plating growing L-form protoplasts on kanamycin-L-form agar medium supplemented with horse serum. Single protoplast colonies were isolated after 2-5 d incubation at $30^{\circ} \mathrm{C}$, and pMD101 was reisolated from the L-form transconjugants.

Polyethylene glycol (PEG) transformation of plasmid pGKS273-3 $\left(\right.$ ampG, $\mathrm{Cm}^{\mathrm{R}}$ ) into $\mathrm{L}$-form strain LVI(pMD101) was carried out according to Klessen et al. (1989), with modification. Transformants were selected by transfer of the PEG-transformation mixture to $30 \mathrm{ml}$ $\mathrm{L}$-form medium containing $20 \mu \mathrm{g}$ chloramphenicol $\mathrm{ml}^{-1}$ and incubation at $37^{\circ} \mathrm{C}$ with slow shaking. Growing L-form protoplasts appearing after $2 \mathrm{~d}$ were spread on $\mathrm{L}$-form agar plates containing $20 \mu \mathrm{g}$ chloramphenicol ml $\mathrm{ml}^{-1}$ and $100 \mu \mathrm{g}$ kanamycin ml $\mathrm{l}^{-1}$. Colonies of transformants $\mathrm{LVI}(\mathrm{pMD} 101+\mathrm{pKGS} 273-3)$ were isolated after $5 \mathrm{~d}$ incubation at $30^{\circ} \mathrm{C}$.

$\beta$-Lactamase techniques. Induction of $\beta$-lactamase by $\beta$-lactam antibiotics, preparation of crude extracts of $\beta$-lactamase from sonicated bacterial cells, and spectrophotometric assays of $\beta$-lactamase activity were performed according to Lindberg et al. $(1985,1987)$. Hydrolysis of the substrates cephalexin $(200 \mu \mathrm{M})$ by enzyme extracts from cells, and nitrocefin $(100 \mu \mathrm{M})$ by excreted $\beta$-lactamase in culture medium, was measured at wavelengths of 260 and $482 \mathrm{~nm}$, respectively. One unit (U) of $\beta$-lactamase hydrolyses $1 \mu \mathrm{mol}$ of the respective substrate $\min ^{-1}$ in $50 \mathrm{~mm}$-sodium phosphate buffer, $\mathrm{pH} 7.0$, at $30^{\circ} \mathrm{C}$. $\beta$-Lactamase excreted from $\mathrm{L}$-form protoplasts grown in $30 \mathrm{ml}$ shake cultures to an $\mathrm{OD}_{578}$ of 0.4 , was measured in samples of clear growth medium after removal of the protoplasts by centrifugation for $15 \mathrm{~min}$ at $6000 \mathrm{~g}$. $\beta$ Lactamase activities in $U$ (ml medium $)^{-1}$ were compared with those in equal volumes of cultures of $P$. mirabilis cells adjusted to the same OD, after liberation of the enzyme by sonication of the cells.

\section{Results and Discussion}

Transconjugation of amp $R$ and $a m p C$ from $C$. freundii on plasmid pMD101 into normal cells and $L$-form protoplasts of $P$. mirabilis

Initial attempts to introduce cloned $a m p R$ and $a m p C$ from $C$. freundii on available $E$. coli host-specific plasmids pNU305 and pNU344 (Lindberg et al., 1985, 1987), into cells of $P$. mirabilis by conventional transformation or electroporation were unsuccessful. This finding agrees with previous reports on the failure or very low efficiency of plasmid transformation into $P$. mirabilis by different techniques (Merrick et al., 1987; Wirth et al., 1989).

However, transconjugation of plasmid pKT231 $\left(\mathrm{Km}^{\mathrm{R}}\right.$ $\mathrm{Sm}^{\mathrm{R}}$ ) with extended host range for Gram-negative bacteria (Bagdasarian et al., 1981) from the donor E. coli S17-1 containing mobilizing function (Simon, 1989) was routinely achieved by liquid mating into whole cells and by filter mating into L-form protoplasts of $P$. mirabilis. Therefore, ampR and $a m p C$ on pNU302 (Lindberg et al., 1985) was re-cloned into pKT231 as described in Methods, to obtain plasmid pMD101 ( $a m p R$ ampC $\mathrm{Km}^{\mathrm{R}}$ $20.8 \mathrm{~kb}$, Fig. 1).

Bacterial transconjugants of $P$. mirabilis VI(pMD101) were selected on kanamycin-containing minimal medium from mating mixtures with the auxotrophic donor $E$. coli S17-1(pMD101). L-form transconjugants could not be isolated in the same way because of their inability to grow on minimal medium. Instead, transconjugants of L-form protoplasts, LVI(pMD101), were obtained as sole survivors of filter mating mixtures in complex medium containing kanamycin plus cycloserine for the selective elimination of the E. coli S17-1(pMD101) donor.

\section{Expression of ampC $\beta$-lactamase from pMD101 in bacterial and $L$-form tranconjugants of $P$. mirabilis}

The presence of an ampC-type gene has been demonstrated in P. mirabilis (Bergström et al., 1983). However, weak and non-inducible expression of the chromosomal

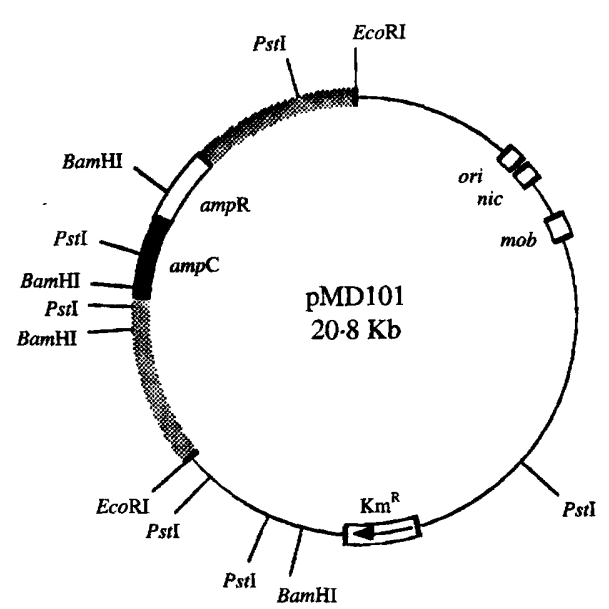

Fig. 1. Mobilizable plasmid pMD101 ( $a m p R$ ampC $\mathrm{Km}^{\mathrm{R}}$ ), containing cloned genes $a m p R$ and $a m p C$ on a $7.5 \mathrm{~kb}$ EcoRI chromosomal fragment from $C$. freundii (stippled segment), inserted into the unique EcoRI site of broad-host-range plasmid pKT231 (13.3 kb, Bagdasarian et al., 1981; thin black segment). From the donor E. coli S17-1(pMD101), plasmid pMD101 was transconjugated into bacteria and L-form protoplasts of $P$. mirabilis VI for assays of $\beta$-lactamase expression in these hosts. 
$\beta$-lactamase has been reported in this organism (Smith, 1969). In agreement with this observation we found that neither cells of $P$. mirabilis VI nor protoplasts of the isogenic L-form strain LVI contained measurable $\beta$ lactamase activity, and induction of the enzyme to higher concentration also did not occur. Thus, expression of any heterologous ampC $\beta$-lactamase from cloned $a m p R$ and $a m p C$ of $C$. freundii was expected to be readily detectable here. Specific activities of constitutive and induced AmpC $\beta$-lactamase isolated from bacterial transconjugants of $P$. mirabilis and of transformants of $E$. coli reference strains are shown in Table 1. The regular function of $a m p R$ and $a m p C$ in pMD101 was demonstrated by the comparable constitutive and hyperinduced expression of $\beta$-lactamase from these genes in pMD101 and pNU305 in the ampD1 mutant $E$. coli SN0301 (Lindberg et al., 1987). Also, typically moderate constitutive and 16-fold induced synthesis of $\beta$-lactamase occurred in the $a m p D$ wild-type strain $E$. coli $\mathrm{HfrH}-$ (pMD101).

In the transconjugant $P$. mirabilis VI(pMD101) the enzyme was synthesized constitutively at low level, and was induced 105 -fold by $\beta$-lactam antibiotic. Also, with the introduction of pMD101, the inhibitory concentrations of $\beta$-lactamase-labile cephalothin and of $\beta$ lactamase-stable cefotaxime increased from 2 and $<2 \mu \mathrm{g}$ $\mathrm{ml}^{-1}$ to $>64$ and $16 \mu \mathrm{g} \mathrm{ml}^{-1}$, respectively, in $E$. coli SN0301, and from 16 and $<0.25 \mu \mathrm{g} \mathrm{ml}^{-1}$ to $>128$ and $1 \mu \mathrm{g} \mathrm{ml}^{-1}$, respectively, in P. mirabilis VI. Obviously, in $P$. mirabilis VI an induction sensor and equivalents of genes for other required functions previously identified in E. coli, Ent. cloacae and C. freundii, such as ampG and $a m p D$, must be present and capable of interacting with $a m p R$ and $a m p C$ of $C$. freundii.

In transconjugants of L-form protoplasts LVI(pMD101), in the absence of an outer membrane and periplasmic space, the $\beta$-lactamase was excreted into the growth medium. Only negligible amounts of enzyme were found in the cytoplasm and membranes of the protoplasts (data not shown). Therefore, expression of $\beta$ lactamase from pMD101 in protoplasts and whole cells was compared by measuring enzyme activities in the growth medium produced by comparable amounts of bacteria and protoplasts (Table 2). In the L-form LVI(pMD101), AmpC $\beta$-lactamase was expressed constitutively, but there was no enzyme induction under conditions where the $\beta$-lactamase in the isogenic bacteria was induced 87 -fold. The much lower enzyme activity in L-form cultures in the presence of inducer resulted from inactivation of the constitutive enzyme by the added cefoxitin, presumably by stable acylation. This was suggested by the immediate lowering of the activity of the constitutive $\beta$-lactamase when cefoxitin at the concentration used for induction was added to the L- form medium after the protoplasts had been removed by sedimentation.

Non-inducibility of $\beta$-lactamase in the L-form is not due to defective ampG or the loss of penicillin-binding proteins

The non-inducibility of $\beta$-lactamase in the L-form could possibly have been caused by the spontaneous loss of an additional induction factor, such as the $a m p G$-mediated signal transducer, or of a penicillin-binding protein serving as induction sensor. Therefore, cloned ampG from $E$. coli on plasmid pGKS273-3 (G. Korfmann, personal communication) which complements the noninducibility of ampG-defective $E$. coli mutants (Lindquist et al., 1993), was introduced into protoplasts of LVI(pMD101) by PEG transformation. However, these $a m p G$ transformants remained non-inducible (Table 2). Thus, there was no evidence of an ampG defect in L-form strain LVI. It is, of course, possible that $a m p G$ from $E$. coli is unable to complement in $P$. mirabilis.

Previous studies have also shown that all essential penicillin-binding proteins for peptidoglycan synthesis and most or all non-essential ones are present in different Proteus L-form strains (Martin et al., 1980; Rousset et al., 1982). If an induction signal interacting with ampG or its product could arise by direct, cell-wall-independent emission from an inducer-sensing penicillin-binding protein after the binding of inducing $\beta$-lactam, this should also be possible in the L-form.

Loss of constitutive overproduction of $\beta$-lactamase in the protoplast $L$-form

Because of the generally weak expression of AmpC $\beta$ lactamase in $P$. mirabilis a low level of enzyme induction in the L-form could possibly be overlooked. Therefore we attempted to detect inducibility with higher sensitivity in a protoplast L-form derived from $\beta$-lactamaseoverproducing mutants of $P$. mirabilis VI, analogous to the ampD-defective mutants of $C$. freundii and $E$. coli (Lindberg et al., 1987; Lindquist et al., 1989b) and Ent. cloacae (Honoré et al., 1989) with high semi-constitutive or hyperinducible $\beta$-lactamase.

Selection for resistance to cefotaxime $\left(2-16 \mu \mathrm{g} \mathrm{ml}^{-1}\right)$ in the presence of kanamycin $\left(100 \mu \mathrm{g} \mathrm{ml}^{-1}\right)$ was used to isolate $\beta$-lactamase-overproducing mutants of $P$. mirabilis(pMD101) (Lindberg et al., 1987). Platings of $3 \times 10^{9}$ cells were made on high-glucose and $\mathrm{NaCl}$-deficient agar medium with antibiotics on which the swarming of $P$. mirabilis was suppressed and separate colonies were formed. Among eight resistant isolates tested, two strains, $P$. mirabilis VI-R1(pMD101) and VI-R2- 
Table 1. Constitutive and induced expression of $A m p C$ $\beta$-lactamase from cloned ampR and ampC of $C$. freundii in E. coli and P. mirabilis

\begin{abstract}
$\beta$-Lactam antibiotics with known inducing potency, 6-aminopenicillanic acid (Lindberg \& Normark, 1987), and cefoxitin and imipenem (Martin et al., 1988), were tested at different concentrations. Highest induction without simultaneous cell wall damage was obtained by 6-aminopenicillanic acid in $E$. coli and by cefoxitin in $P$. mirabilis. Induction in this experiment was with $250 \mu \mathrm{g}$ 6-aminopenicillanic acid mi $\mathrm{I}^{-1}$ in $E$. coli and with $10 \mu \mathrm{g}$ cefoxitin $\mathrm{ml}^{-1}$ in $P$. mirabilis. Results of triplicate measurements with the substrate cephalexin are shown \pm sD. n.m.a., No measurable activity.
\end{abstract}

\begin{tabular}{lccc}
\hline & & \multicolumn{2}{c}{$\beta$-Lactamase, sp. act. } \\
& $\begin{array}{c}\text { Plasmid-borne } \\
\text { ampR } \text { and } \\
\text { ampC }\end{array}$ & \multicolumn{2}{c}{$\mathrm{U}(\mathrm{mg}$ protein) } \\
\cline { 3 - 4 } Bacteria & & Constitutive & Induced \\
\hline E. coli & - & n.m.a. & n.m.a. \\
SN0301 (ampD1) & + & $1 \cdot 1 \pm 0 \cdot 1$ & $14 \cdot 8 \pm 1 \cdot 1$ \\
SN0301(pNU305) & + & $2 \cdot 0 \pm 0 \cdot 3$ & $12 \cdot 9 \pm 1 \cdot 4$ \\
SN0301(pMD101) & + & n.m.a. & n.m.a. \\
HfrH & + & $0 \cdot 16 \pm 0 \cdot 02$ & $2 \cdot 5 \pm 0 \cdot 2$ \\
HfrH(pMD101) & & & \\
$P$. mirabilis & - & n.m.a. & n.m.a. \\
VI & - & n.m.a. & n.m.a. \\
VI(pKT231) & + & $0 \cdot 02 \pm 0.01$ & $2 \cdot 1 \pm 0 \cdot 1$ \\
VI(pMD101) & + & $8 \cdot 8 \pm 1 \cdot 8$ & $11 \cdot 4 \pm 1 \cdot 2$ \\
VI-R1(pMD101) & + & $6.9 \pm 1 \cdot 1$ & $18 \cdot 5 \pm 1 \cdot 5$ \\
VI-R2(pMD101) & + & & \\
\hline
\end{tabular}

Table 2. Difference in inducibility of AmpC $\beta$-lactamase from cloned ampR and ampC on $p M D 101$ in normal bacteria and in L-form protoplasts of P. mirabilis $V I$

Induction was with $10 \mu \mathrm{g}$ cefoxitin $\mathrm{ml}^{-1}$. Activity of $\beta$-lactamase excreted from the L-form protoplasts was determined in the growth medium. The activity of solubilized enzyme from a comparable quantity of bacteria was measured after sonication of the cells. Values of triplicate measurements with the substrate nitrocefin are shown \pm SD.

\begin{tabular}{|c|c|c|}
\hline & \multicolumn{2}{|c|}{$\begin{array}{c}10^{-3} \times \beta \text {-Lactamase activity } \\
\left(\mathrm{U} \mathrm{ml}^{-1}\right)\end{array}$} \\
\hline & Constitutive & Induced \\
\hline $\begin{array}{l}\text { Bacterium } \\
\text { VI(pMD101) }\end{array}$ & $5 \cdot 1 \pm 0 \cdot 5$ & $442 \pm 35$ \\
\hline $\begin{array}{l}\text { L-form } \\
\text { LVI(pMD101) } \\
\text { LVI(pMD101 + pGKS 273-3) } \\
\quad(\text { ampG) }\end{array}$ & $\begin{array}{l}12 \cdot 9 \pm 1 \cdot 8 \\
13 \cdot 4 \pm 2\end{array}$ & $\begin{array}{c}2 \cdot 4 \pm 0 \cdot 8 \\
4 \pm 1\end{array}$ \\
\hline
\end{tabular}

(pMD101), surviving on 2 and $8 \mu$ g cefotaxime $\mathrm{ml}^{-1}$, respectively, showed highly elevated constitutive $\beta$ lactamase activity and limited further inducibility (Table 1). The minimal inhibitory concentration of cefotaxime for these strains was $>32 \mu \mathrm{g} \mathrm{ml}^{-1}$, in contrast to $<0 \cdot 25$ and $1 \mu \mathrm{g} \mathrm{ml}^{-1}$ for $P$. mirabilis VI and VI(pMD101), respectively. Thus, $P$. mirabilis VI-R1(pMD101) and VIR2(pMD101) resembled E. coli mutant SN0302 (ampD2) with high semi-constitutive $\beta$-lactamase expression from cloned $a m p R$ and $a m p C$ (Lindberg et al., 1987; Lindquist et al., 1989b). Therefore, the $\beta$-lactamase-overproducing strains of $P$. mirabilis VI were tentatively assumed to be defective in $a m p D$. However, this remains to be proven by complementation when a wild-type ampD-bearing plasmid becomes available which can be introduced into $P$. mirabilis and is compatible with pMD101.

Conversion of $P$. mirabilis VI-R1(pMD101) and VI$\mathrm{R} 2(\mathrm{pMD101})$ to the irreversible, wall-less protoplast $\mathrm{L}$ form was carried out in two steps of progressive disorganization of the cell wall, different from the traditional technique of long-term exposure to high concentrations of benzyl penicillin (Taubeneck, $1962 a, b$; Martin, 1983). First, the bacteria were converted to the reversible spheroplast $\mathrm{L}$-form with residual but defective cell walls during growth on L-form agar medium containing the $\beta$-lactamase-stable monobactam antibiotic aztreonam at a concentration of $100 \mu \mathrm{g} \mathrm{ml}^{-1}$. The spheroplasts were then adapted to growth in the same liquid medium (Martin \& Gmeiner, 1979; Martin, 1983; Huber \& Martin, 1986). For the maintenance of plasmid pMD101 in the spheroplasts, $100 \mu \mathrm{g}$ kanamycin $\mathrm{ml}^{-1}$ was present in all media.

In a second step, viable wall-less protoplasts were isolated from the spheroplast culture by complete inactivation of all essential penicillin-binding proteins and inhibition of peptidoglycan synthesis. This was achieved by growth in the presence of aztreonam with preferred binding to penicillin-binding protein 3 and the carbapenem antibiotic imipenem at a concentration of $125 \mu \mathrm{g} \mathrm{ml}^{-1}$, which simultaneously inactivates penicillinbinding proteins 1A, 1B and 2 (Huber, 1985; Huber \& Martin, 1986).

After initial incubation for $5 \mathrm{~d}$ in liquid medium with both $\beta$-lactams and kanamycin, growth of $\mathbf{L}$-form protoplasts was obtained which were subcultured repeatedly in the same medium. Upon transfer to $\beta$-lactamfree medium and subsequent subculture, growth in the Lform continued in all isolates, and no reversion to the bacterial form took place. This suggested that the stable protoplast L-form strains LVI-R1(pMD101) and LVIR2(pMD101) had been obtained. Surprisingly, no constitutive or inducible $\beta$-lactamase activity could be detected in the growth medium or in the protoplasts of such Lform cultures derived from the $\beta$-lactamase-overproducing $P$. mirabilis mutants. Loss of plasmid pMD101 from the L-form was excluded as the cause of the absence of the enzyme. Plasmid DNA was isolated from protoplasts of LVI-R1(pMD101) and LVI-R2(pMD101) and transformed into $E$. coli SN0301 (ampD1) with 
selection for kanamycin resistance. In the transformants $\beta$-lactamase was expressed in the typical hyperinducible fashion.

The total absence of $\beta$-lactamase in L-forms LVIR1(pMD101) and LVI-R2(pMD101) remains unexplained. One may speculate that even constitutive expression of AmpC $\beta$-lactamase requires a signal at low level, and that its formation also involves low-molecularmass components of the cytoplasmic or membranebound stages of the peptidoglycan biosynthetic pathway which persist in the cell-wall-less L-form. Conversion of $P$. mirabilis VI-R1 and VI-R2 into the L-form by total inhibition of the essential penicillin-binding proteins may have eliminated such required metabolites which have remained functional in the original, benzyl-penicillininduced L-form strain LVI. As yet, no information on such differences in P. mirabilis L-forms is available. They may resemble the differences in the state of peptidoglycan precursor molecules and biosynthetic enzymes that have been characterized in different L-form strains of Bacillus subtilis and Bacillus licheniformis (Ward, 1975).

Assuming that $\beta$-lactamase overproduction in $P$. mirabilis mutants VI-R1 and VI-R2 are due to defective $a m p D$, the observed loss of $\beta$-lactamase expression and overproduction in the protoplast L-from descendants of VI-R 1 and VI-R2 also agrees with the concept of a 'late' function of $a m p D$ depending on the arrival of a peptidoglycan-derived induction signal, as suggested in the model of Lindberg et al. (1988).

\section{Proposal of a general, peptidoglycan-related mechanism of $\beta$-lactamase induction}

The reported results support the notion that induction in Gram-negative bacteria is an indirect process dependant on the metabolism of the cell wall. From the inhibition of synthesis of cell-wall peptidoglycan by $\beta$-lactam antibiotics, one or several derouted and possibly degraded precursors or breakdown products may arise and these may function as secondary signal (autoinducer, Lindberg et al., 1988) for $\beta$-lactamase induction. Obviously, this possibility does not exist in the wall-less L-form protoplasts. It remains possible, of course, that noninducibility in the L-form is connected with the absence of a still unknown induction sensor or other essential factor that has been lost together with the outer membrane and periplasm.

However, the concept that induction of $\beta$-lactamase is initiated by disturbance of peptidoglycan synthesis is also supported by recent observations of 'unspecific' $\beta$ lactamase induction by glycine and D-amino acids in Ent. cloacae (Gatus et al., 1986; Ottolenghi, 1993) and in hyperinducible $E$. coli SN0301 ( $a m p D 1)$ (pNU305) carrying cloned $a m p R$ and $a m p C$ from $C$. freundii (Martin \&
Schmidt, 1993). Most importantly, it has been shown that $\beta$-lactamase was equally non-inducible by $\beta$-lactam and by glycine or D-methionine in the ampG-defective mutant E. coli SN0301-1(pNU305) (Schmidt, 1991; Martin \& Schmidt, 1993). Thus, induction by both types of inhibitors of peptidoglycan synthesis depends on the function of the ampG-encoded signal transducer.

Glycine and D-amino acids have been extensively characterized as inhibitors of peptidoglycan synthesis (Hammes et al., 1973; Trippen et al., 1976). The mechanism of this inhibition, viz. competitive interference with the construction of peptide side chains of the peptidoglycan, differs drastically from the action of $\beta$-lactam antibiotics. Moreover, no mechanism is known by which glycine and D-amino acids or a product of their inhibitory action could interact with an inductionsensing penicillin-binding protein.

The available data make it attractive to assume a general pathway of $\beta$-lactamase induction as a response to altered conditions of peptidoglycan synthesis in Gramnegative bacteria. Presumably, in spite of their different mechanisms, the different inhibitors with the simultaneous function as $\beta$-lactamase inducers cause the formation of certain peptidoglycan catabolites of sufficiently similar structure and potential for interaction with $\operatorname{amp} G$ or its product. A requirement for such specifically structured induction signals may also explain the high inducing capacity of certain $\beta$-lactams, such as cefoxitin and other cephamycins, and imipenem, in contrast to low induction by other, structurally different $\beta$-lactams (Gootz \& Sanders, 1983; Martin et al., 1988). The selective affinities of the effectively inducing $\beta$ lactams for penicillin-binding proteins and the resulting specific peptidoglycan damage may lead to the most efficient production of an induction signal.

This work was supported by the Deutsche Forschungsgemeinschaft.

\section{References}

Bagdasarian, M., Lurz, R., Rückert, B., Franklin, F. C. H., Bagdasarian, M. M., Frey, J. \& Timmis, K. N. (1981). Specific purpose plasmid cloning vectors II. Broad host range, high copy number, RSF1010-derived vectors, and a host vector system for gene cloning in Pseudomonas. Gene 16, 237-247.

Bergström, S., Lindberg, F., Olson, O. \& Normark, S. (1983). Comparison of the overlapping frd and ampC operons of Escherichia coli with the corresponding DNA sequences in other Gram-negative bacteria. Journal of Bacteriology 155, 1297-1305.

Everett, M. J., ChOPRA, I. \& BENNETT, P. M. (1990). Induction of the Citrobacter freundii Group I $\beta$-lactamase in Escherichia coli is not dependent on entry of $\beta$-lactam into the cytoplasm. Antimicrobial Agents and Chemotherapy 34, 2429-2430.

Gatus, B. J., Bell, S. M. \& Jimenez, A. S. (1986). Comparison of glycine enhancement with cefoxitin induction of $\beta$-lactamase production in Enterobacter cloacae ATCC 13047. Journal of Antimicrobial Chemotherapy 21, 163-170.

Gootz, T. D. \& SANDERS, C. C. (1983). Characterization of $\beta$-lactamase 
induction in Enterobacter cloacae. Antimicrobial Agents and Chemotherapy 23, 91-97.

Grabow, W. O. K. \& SMIT, J. A. (1967). Methionine synthesis in Proteus mirabilis. Journal of General Microbiology 46, 47-57.

Hammes, W., SChleifer, K. H. \& KandleR, O. (1973). Mode of action of glycine on the biosynthesis of peptidoglycan. Journal of Bacteriology 116, 1029-1053.

HaNaHAN, D. (1983). Studies on transformation of Escherichia coli with plasmids. Journal of Molecular Biology 166, 557-580.

HofsChNeIder, P. H. \& MaRTin, H. H. (1968). Diversity of surface layers in L-forms of Proteus mirabilis. Journal of General Microbiology 51, 23-33.

Honoré, N., Nicolas, M. H. \& Cole, S. T. (1986). Inducible cephalosporinase production in clinical isolates of Enterobacter cloacae is controlled by a regulatory gene that has been deleted from Escherichia coli. EMBO Journal 5, 3709-3714.

HoNoré, N., NrCOlas, M. H. \& COLE, S. T. (1989). Regulation of enterobacterial cephalosporinase production: the role of a membrane-bound sensory transducer. Molecular Microbiology 3, 11211130.

HUBER, K. (1985). Quantitative Bewertung der Funktion von Penicillinbindeproteinen an der Sphäroplasten-L-Form von Proteus mirabilis nach Einwirkung verschiedener Klassen von $\beta$-Laktam-Antibiotika. $\mathrm{PhD}$ thesis, Technische Hochschule Darmstadt, Germany.

HuBER, K. \& MarTIN, H. H. (1986). State of peptidoglycan in spheroplasts of Proteus mirabilis grown in the presence of different $\beta$ lactam antibiotics. In Biological Properties of Peptidoglycan, pp. 187-190. Edited by P. H. Seidl \& K. H. Schleifer. Berlin, New York: Walter de Gruyter.

JAURIN, B. \& GRUNDSTRÖM, T. (1981), ampC cephalosporinase of Escherichia coli K-12 has a different evolutionary origin from that of $\beta$-lactamases of the penicillinase type. Proceedings of the National Academy of Sciences of the United States of America 78, 4897-4901.

Klessen, C., Schmidt, K. H., Gumpert, J., Grosse, H. H. \& Malke, H. (1989). Complete secretion of activable bovine prochymosin by genetically engineered L-forms of Proteus mirabilis. Applied and Environmental Microbiology 55, 1009-1015.

KorfmanN, G. \& SANDERs, C. C. (1989). ampG is essential for high level expression of AmpC $\beta$-lactamase in Enterobacter cloacae. Antimicrobial Agents and Chemotherapy 33, 1946-1951.

KROLL, H. P., GmenNer, J. \& MARTIN, H. H. (1980). Membranes of the protoplast L-form of Proteus mirabilis. Archives of Microbiology 127, 223-229.

LINDBERG, F. \& NoRmarK, S. (1987). Common mechanism of ampC $\beta$ lactamase induction in enterobacteria: regulation of the cloned Enterobacter cloacae P99 $\beta$-lactamase gene. Journal of Bacteriology 169, 758-763.

LinDBERG, F., WestMAN, L. \& NoRMARK, S. (1985). Regulatory components in Citrobacter freundii ampC $\beta$-lactamase induction. Proceedings of the National Academy of Sciences of the United States of America 82, 4620-4624.

LINDBERG, F., LiNDQUIST, S. \& NoRMARK, S. (1987). Inactivation of the ampD gene causes semiconstitutive overproduction of the inducible Citrobacter freundii $\beta$-lactamase. Journal of Bacteriology 169, 1923-1928.

LINDBERG, F., LINDQUIST, S. \& NoRMARK, S. (1988). Genetic basis of induction and overproduction of chromosomal class I $\beta$-lactamase in non-fastidious Gram-negative bacilli. Reviews of Infectious Diseases 10, 782-785.

Lindquist, S., LindBerg, F. \& NoRmarK, S. (1980a). Binding of the Citrobacter freundii AmpR regulator to a single DNA site provides both autoregulation and activation of the inducible ampC $\beta$ lactamase gene. Journal of Bacteriology 171, 3746-3753.

LindQuist, S., Galleni, M., LindBerg, F. \& Normark, S. (1989b). Signalling proteins in enterobacterial AmpC $\beta$-lactamase regulation. Molecular Microbiology 3, 1091-1102.

Lindquist, S., Weston-Hafer, K., Schmidt, H., Piel, C., Korfmann, G., Erickson, J., Sanders, C., Martin, H. H. \& Normark, S. (1993). AmpG, a signal transducer in chromosomal $\beta$-lactamase induction. Molecular Microbiology 9, 703-715.
Low, B. K. (1973). Rapid mapping of conditional and auxotrophic mutants in Escherichia coli K12. Journal of Bacteriology 113, $798-812$.

Mandel, M. \& Higa, A. (1970). Calcium-dependent bacteriophage DNA infection. Journal of Molecular Biology 53, 159-162.

MarTIN, H. H. (1964). Composition of the mucopolymer in the cell walls of the unstable and stable L-forms of Proteus mirabilis. Journal of General Microbiology 36, 441-450.

Martin, H. H. (1983). Protoplasts and spheroplasts of Gram-negative bacteria, with special emphasis on Proteus mirabilis. In Protoplasts 1983, Lecture Proceedings, Experientia Supplementum, vol. 46, pp. 213-225. Edited by I. Potrykus, C. T. Harms, A. Hinnen, R. Hütter, P. J. King \& R. D. Shillito. Basel: Birkhäuser Verlag.

Martin, H. H. \& Gmeiner, J. (1979). Modification of peptidoglycan structure by penicillin action in cell walls of Proteus mirabilis. European Journal of Biochemistry 95, 487-495.

MARTIN, H. H. \& SchMidT, H. (1993). Disturbance of peptidoglycan synthesis by glycine and D-methionine creates a signal for the ampGmediated induction of AmpC- $\beta$-lactamase in Escherichia coli. In Bacterial Growth and Lysis-Metabolism and Structure of the Bacterial Sacculus, pp. 341-346. Edited by M. A. de Pedro, J. V. Höltje \& W. Löffelhardt. New York: Plenum Publishing Co.

MARTIN, H. H., MaSKos, C. \& BuRGER, R. (1975). D-Alanyl-D-alanine carboxypeptidase in the bacterial form and L-form of Proteus mirabilis. European Journal of Biochemistry 55, 465-473.

Martin, H. H., Schilf, W. \& SchiEFER, H. G. (1980). Differentiation of Mycoplasmatales from bacterial protoplast $L$-forms by assay for penicillin-binding proteins. Archives of Microbiology 127, 297-299.

Martin, H. H., Schmid, B., BRäutigam, S., Noguchi, H. \& MATSUHASH, M. (1988). Initiation of induction of chromosomal $\beta$ lactamase by binding of inducing $\beta$-lactam antibiotics to low molecular weight penicillin-binding proteins. In Antibiotic Inhibition of Bacterial Cell Surface and Assembly, pp. 494-501. Edited by P. Actor, L. Daneo-Moore, M. L. Higgins, M. R. J. Salton \& G. D. Shockman. Washington, DC: American Society for Microbiology.

Merrick, M. J., Gibbins, J. R. \& Postgate, J. R. (1987). A rapid and efficient method for plasmid transformation of Klebsiella pneumoniae and Escherichia coli. Journal of General Microbiology 133, 20532057.

NAYLOR, P. G. D. (1964). The effect of electrolytes or carbohydrates in a sodium chloride deficient medium on the formation of discrete colonies of Proteus and the influence of these substances on growth in liquid culture. Journal of Applied Bacteriology 27, 422-431.

OTrOLENGHI, A. C. (1993). In Enterobacter cloacae alterations induced by glycine and $D$-amino acids in the composition and structure of peptidoglycan are accompanied by induction of chromosomal $\beta$. lactamase. A model involving $f t s Z$ and septation. In Bacterial Growth and Lysis-Metabolism and Structure of the Bacterial Sacculus, pp. 347-354. Edited by M. A. de Pedro, J. V. Höltje W. Löffelhardt. New York: Plenum Publishing Co.

Rousset, A., NguYen-Disteche, M., Minck, R. \& GhuYsen, J. M. (1982). Penicillin-binding proteins and carboxypeptidase/transpeptidase activities in Proteus vulgaris P18 and its penicillin-induced stable L-forms. Journal of Bacteriology 152, 1042-1048.

Sambrook, J., Fritsch, E. F. \& Maniatis, T. (1989). Molecular Cloning: A Laboratory Manual, 2nd edn. Cold Spring Harbor, NY: Cold Spring Harbor Laboratory.

Schmid, H. (1991). Defektmutationen im Schlüsselgen ampG der $\beta$ Laktamase-Induktion bei Escherichia coli-Kartierung, Klonierung und Sequenzierung von Mutantengenen. $\mathrm{PhD}$ thesis, Technische Hochschule Darmstadt, Germany.

SIMON, R. (1989). High frequency mobilization of Gram-negative bacterial replicons by the in vitro constructed Tn 5 -Mob transposon. Molecular and General Genetics 196, 413-420.

SMiTH, J. T. (1969). R-factor gene expression in Gram-negative bacteria. Journal of General Microbiology 55, 109-120.

SYKES, R. B. \& SMTTH, J. T. (1979). Biochemical aspects of $\beta$-lactamases from Gram-negative organisms. In Beta-Lactamases pp. 369-401. Edited by J. M. T. Hamilton-Miller \& J. T. Smith. London: Academic Press.

TAUBEnECK, U, (1962a). Untersuchungen über die L-Form von Proteus mirabilis Hauser. I. Die penicillin-induzierten large bodies (Sphäro- 
plasten) und ihre Bedeutung für die Entstehung der L-Form. Zeitschrift für Allgemeine Mikrobiologie 2, 56-76.

TAUBENECK, U. (1962b). Untersuchungen über die L-Form von Proteus mirabilis Hauser. II. Entwicklung und Wesen der L-Form. Zeitschrift für Allgemeine Mikrobiologie 2, 132-156.

Trippen, B., Hammes, W., Schleifer, K. H. \& Kandler, O. (1976). Die Wirkung von D-Aminosäuren auf die Struktur und Biosynthese des Peptidoglycans. Archives of Microbiology 109, 247-261.

Tuomanen, E., Lindquist, S., Sande, M., Gallen, M., Light, K., GAGE, D. \& NoRMARK, S. (1991). Coordinate regulation of $\beta$ - lactamase induction and peptidoglycan composition by the amp operon. Science 251, 201-204.

WARD, J. B. (1975). Peptidoglycan synthesis in L-phase variants of Bacillus licheniformis and Bacillus subtilis. Journal of Bacteriology 124, 668-678.

WiRTH, R., FrIESENEGGer, A. \& FiEDLER, S. (1989). Transformation of various species of Gram-negative bacteria belonging to 11 different genera by electroporation. Molecular and General Genetics 216, 175-177. 